\title{
The Heritability of Life History Strategy: \\ The K-Factor, Covitality, and Personality
}

\author{
Aurelio José Figueredo, ${ }^{*}$ Geneva Vásquez, Barbara Hagenah Brumbach, and \\ Stephanie M. R. Schneider
}

\author{
Department of Psychology, University of Arizona, Tucson, Arizona
}

ABSTRACT: Archival data from the MIDUS survey (Brim et al., 2000), a nationally representative sample, on $309 \mathrm{MZ}$ and $333 \mathrm{DZ}$ twin pairs aged 25-74 years were used to test the psychometrics and behavioral genetics of life history strategy. We organized 253 of the originally administered 2,000 questions into 30 scales measuring life history traits (e.g., quality of family relationships and altruism towards kin), medical symptoms (e.g., thyroid problems), personality traits (e.g., neuroticism, extraversion, conscientiousness), and social background (e.g., financial security). A single higher-order factor, indicating a general life history strategy, composed of three lower-order factors, was replicated. Factor analyses were then performed on the genetic variance-covariance matrices. We found that (a) a single higher-order factor explained the preponderance of the genetic correlations among the scales and (b) this higher-order factor was itself 68 percent heritable and accounted for 82 percent of the genetic variance among the three component lower-order factors.

\section{INTRODUCTION}

Our purpose is to investigate the genetic basis for the observed positive manifold of correlations underlying individual differences in human life history strategy. These correlated clusters of individual differences account for systematic variation in a wide range of social and healthrelated behaviors, personality factors, and overall health factors (Figueredo, Vásquez, Brumbach, and Schneider, in press). First, we define life history strategy as developed in the biological sciences. Second, we review some previous research indicating the heritability of and genetic correlations among life history traits based on both the database used in the present study, the National Survey of Midlife Development in the United States (MIDUS) survey, and other sources. Third, we de-

*Ethology and Evolutionary Psychology, Department of Psychology, PO Box 210068, University of Arizona, Tueson, Arizona 85721-0068; voice: 520-6217444; fax: 520-621-9306; e-mail: ajf@u.arizona.edu scribe the specific psychometric and behavioral genetic hypotheses that we test using these data and how life history strategy can be used as a unifying theoretical principle for explaining the observed patterns of correlation.

\section{LIFE HISTORY THEORY}

Life History Theory (LHT), a midlevel theory derived from general evolutionary theory (MacArthur and Wilson, 1967; Wilson, 1975), describes an individual's total bioenergetic and material resources as allocated between Somatic Effort, resources devoted to the continued survival of the individual organism, and Reproductive Effort, resources devoted to the production and support of offspring. Reproductive Effort consists of Mating Effort, resources devoted to obtaining and retaining sexual partners, Parental Effort, resources devoted to enhancing the survival of offspring, and Nepotistic Effort, resources devoted 
to enhancing the survival of genetic relatives.

LHT may be illustrated by contrasting the behavioral strategies exhibited by r-selected species, which invest more heavily in reproduction, with $\mathrm{K}$-selected species, which invest heavily in longevity (Pianka, 1970). By this theory, r-selected species evolved under unstable and unpredictable conditions, leading to a strategy focusing on the production of genetically similar individuals (offspring quantity). Rabbits, for example, exhibit rapid sexual development, high fertility, low parental investment, high infant mortality, low interbirth interval, short lives, generally small size, less group cohesion, and less competition for resources because, historically, they evolved under unstable conditions where short-term strategies paid off. Conversely, K-selected species evolved under stable and predictable conditions, leading to a strategy focusing on the survival of genetically similar individuals (offspring quality); thus they do not generally exceed the carrying capacity of their environment. Elephants, for example, exhibit slow, delayed sexual development, low fertility, high parental investment, low infant mortality, high interbirth interval, greater longevity, large body size, high group cohesion, and intense competition for resources because, historically, they evolved in stable environments where long-term strategies paid off.

LHT was originally developed by MacArthur and Wilson (1967) to explain variation in life histories through densitydependent selection; Pianka (1970) later elaborated and described clusters of life history traits as either r-selected or K-selected. According to these theorists, population density was the primary force selecting for life history traits (MacArthur and Wilson, 1967; Pianka, 1970). Other theorists later suggested that the original $\mathrm{r}-\mathrm{K}$ theory was incomplete and stated that variation in predation was an important parameter that needed to be included in the model (Reznick, Bryant, and Bashey, 2002). By incorporating this parameter, demographic theory was now the predominant view for understanding mechanisms underlying life history strategies (Stearns, 1992). This theory focuses on age-structured populations, specifically attending to differential mortality rates across age groups (Charlesworth, 1980). Current LHT tends to incorporate features from both $\mathbf{r}-\mathrm{K}$ and demographic theories. Integrating age-specific mortality parameters provided better predictions and mechanistic explanations for the relationship between the environment and life history strategy (Wilbur, Tinkle, and Collins, 1974). As a model of ecological causation, Pianka's (1970) version of $r-K$ theory has thus been extensively elaborated and revised since the 1980s (Reznick, Bryant, and Bashey, 2002; Stearns, 1992). Nevertheless, as an organizing principle for empirical description, the general patterning of life history traits has gained continued support (e.g., Rushton, 2004).

Hence, as compared to r-selected organisms, K-selected organisms are expected to manifest the benefits of their pattern of resource allocation in terms of greater phenotypic fitness. K-selected organisms should thus be more individually viable on a variety of indicators of general health, developmental stability, and mental and physical function (MacArthur and Wilson, 1967; Rushton, 1985, 2000; Thornhill and Palmer, 2004). As applied to humans, LHT predicts that family structure, intelligence, sexual behavior, and personality will be interrelated to 
produce an overarching life history strategy (Rushton, 1985, 2000; Thornhill and Palmer, 2004). Thus, LHT predicts that many psychosocial traits (specifically, life history traits) will accumulate nonrandomly. LHT suggests that natural and sexual selection will combine life history traits into functional composites representing coadapted reproductive strategies. Natural and sexual selection will therefore shape many aspects of an individual's approach to adaptive problems presented by the physical and social environment and cause specific psychosocial traits to intimately intertwine and to appear in clusters.

LHT, therefore, predicts that multivariate correlational techniques will detect specific functional, cognitive, affective, and behavioral composites. The analyses used in previous investigations of predictions derived from LHT, however, have generally been restricted to univariate correlational analyses in the service of testing specific causal hypotheses (e.g., Quinlan, 2003) which cannot fully describe or explicate the wider pattern of correlations between variables predicted by LHT. In contrast, we proposed that a single common factor, the K-Factor, underlies a variety of life history indicators, including an assortment of sexual, reproductive, parental, and social behaviors (Figueredo, Sefcek, Vásquez, Brumbach, King, and Jacobs, 2005).

For example, one previous study on the connection between personality and life history strategy on a sample of university students (Figueredo, Vásquez, Brumbach, Sefcek, Kirsner, and Jacobs, 2005) determined that variation in life history strategy accounted for a significant proportion (92 percent) of the variance in attachment to and investment from the biological father, attachment to and investment from any father figure other than the biological father, adult romantic partner attachment, mating effort, Machiavellianism, and risk taking propensity. Similarly, a constructive replication conducted in Northern Mexico (Hermosillo, Sonora) on a sample of adults with children detected a single common factor that explained a significant proportion (again 92 percent) of the reliable variance in the characteristics selected as indicators of life history strategy (Tal, Hill, Figueredo, Frías-Armenta, CorralVerdugo, in press). This study used several scales derived from the MIDUS Survey (Brim et al., 2000) in combination with several other published measures previously used with another sample of residents of Hermosillo in a study of domestic violence (Figueredo et al., 2001). These latter scales included parental investment as a child from both mother and father, parental investment in one's own children, family social support, friends' social support, general altruism, and long term planning propensity.

Most recently, a psychometric test of life history theory as applied to human individual differences was performed using the MIDUS survey (Brim et al., 2000). The National Survey of Midlife Development in the United States was designed to describe events, beliefs, and individual differences in a large, nationally representative sample of Americans between adolescence and late adulthood (Brim, Ryff, and Kessler, 2004). The primary focus of the MIDUS survey was to investigate those factors which contribute to overall well-being and health factors in the social behaviors of midlife Americans (Rossi, 2001). The measures of wellbeing included indicators of physical health, psychological health, and social well-being, both within the family and in 
the community at large (Brim et al., 2004). To this end, the MIDUS survey consisted of many scales measuring life history domains including socioeconomic status, demographic variables, childhood experiences, sexuality, social relationships, community participation, religiosity, parenting and relationship styles, personality, and health behaviors and history (Brim et al., 2004). The end result is a battery of measures which provides information on three life domains 1) social responsibilities and activity within and beyond the family, 2) health and health behaviors, both mental and physical, and 3) psychological well-being.

In this study, twenty scales measuring cognitive and behavioral dimensions theoretically related to life history strategy were constructed using items from the MIDUS survey hypothesized (Figueredo, Vásquez, Brumbach, and Schneider, in press). These scales were used to construct a single common factor, the K-Factor, which accounted for 70 percent of the reliable variance. The scales used included Mother Relationship Quality, Father Relationship Quality, Marital Relationship Quality, Children Relationship Quality, Family Support, Altruism Towards Kin, Friends Support, Altruism Towards Non-Kin, Close Relationship Quality, Communitarian Beliefs, Religiosity, Financial Status, Health Control, Agency, Advice Seeking, Foresight/Anticipation, Insight Into Past, Primary Control/ Persistence, Flexible/Positive Reappraisal, and Self-Directedness/Planning. Another common factor, Covitality, was constructed from scales for Subjective WellBeing, Negative Affect, Positive Affect, General Health, and Medical Symptoms. Finally, a single general factor, Personality, was constructed from scales for Openness to Experience, Conscientious- ness, Extraversion, Agreeableness, and Neuroticism. The K-Factor, Covitality factor, and general Personality factor were found to be significantly correlated with each other, supporting the hypothesis that a high-K life history strategy predicted high somatic effort and was also manifested in behavioral display. Thus, a single higher-order common factor, the Super-K Factor, was constructed to encompass the K-Factor, Covitality factor, and Personality factor.

These previous studies demonstrate the presence of a single psychometric latent common factor underlying individual variation in human life history strategy as measured by our instruments. Moreover, the analyses demonstrated that the K-Factor shows some cross-cultural validity. However, none of these results indicate whether and to what extent the observed covariation in life history traits is either genetic or environmental in origin.

\section{BEHAVIOR GENETIC EVIDENCE FOR HERITABILITY OF LIFE HISTORY TRAITS}

Rowe (2000) reported heritabilities of 0.44 for menarchal age and 0.40 for pubertal timing, with a negligible effect of shared environment. Kirk, Blomberg, Duffy, Heath, Owens, and Martin (2001) reported heritabilities of 0.50 for age at menarche, 0.23 for age at first reproduction, and 0.45 for age at menopause. They also found substantial heritable variation in fitness, with 0.39 of the variance attributable to additive genetic effects and most of the remainder attributable to the effects of non-shared environment. Rodgers, Hughes, Kohler, Christensen, Doughty, Rowe, and Miller (2001) reviewed both the theory and the evidence for heritable differentials in human fertil- 
ity, attributing much of this influence to genetically-mediated behavioral precursors. Significant heritabilities have been reported for many of these behavioral precursors to differential fertility, including sexual behavior, marriage and divorce, fertility desires, fertility ideals and expectations, age of first explicit attempt to get pregnant, completed family size, and parenting behavior.

Behavior genetics studies have demonstrated that many reproductively-relevant psychological traits are heritable, including social attitudes, personality, and mental illness (Bouchard, 2004). More specifically, several behavioral life history traits have been identified in behavior genetic studies to be partially heritable. Some of these traits include social attitudes, religiosity, propensity toward long term relationships, rearing environment, personality, impulse control, impulsivity and sensation seeking, and social deviance in general.

Bouchard, Segal, Tellegen, McGue, Keyes, and Krueger (2004) review and discuss several studies that demonstrate the heritability of social attitudes. Research that used several measures of religiosity to compare $\mathrm{MZ}$ and $\mathrm{DZ}$ twins reared apart or reared together found that about 50 percent of the variance could be accounted for by genetic contributions (Waller, Kojetin, Bouchard, Lykken, and Tellegen, 1990). Intrinsic and Extrinsic religiousness scales were used to determine heritability coefficients utilizing $\mathrm{MZ}$ and $\mathrm{DZ}$ twins reared apart. The Minnesota Study of Twins Reared Apart found the heritability to be 0.43 (Intrinsic religiousness) and 0.39 (Extrinsic religiousness) (Bouchard, McGue, Lykken, and Tellegen, 1999).

In a study using singletons and twins, evidence suggests that the propensity to marry is heritable. In addition, they found that there is a genetic influence on the phenotypic relationship between personality and propensity to marry (Johnson, McGue, Krueger, and Bouchard, 2004). Furthermore, using $\mathrm{MZ}$ and $\mathrm{DZ}$ twins reared apart, it was determined that about 44 percent of the variance of one's perception of support from the childhood rearing environment could be attributed to genetic factors (Hur and Bouchard, 1995). Another study found in twins reared apart that, "family environmental measures appear to be heritable because personality genes influence the way people shape and recall their rearing environments." How one remembers their rearing environment is partially heritable and that heritability is accounted for by the variance in heritability of personality (Krueger, Markon, and Bouchard, 2003).

There have been numerous studies that have shown personality itself to be partially influenced by genetic factors. In a review of major studies in this area, the Big Five personality traits (using standard instruments), appear to have 40-50 percent of the variance accounted for by genetic factors (Bouchard, 1993). The Control Scale from the MPQ (Tellegen, 1982) and the Zuckerman (1979) Sensation Seeking Scale were used to examine the heritability of impulsivity and sensation seeking. For analyses, MZ and DZ twins reared apart and singletons were utilized. The proportion of genetic variance of the Control Scale in common with the Sensation Seeking Scale was 55 percent; the remainder of the genetic variance ( 45 percent) was genetic variance specific to the Control Scale (Hur and Bouchard, 1997, p. 455).

Furthermore, Rowe and Rodgers (1989) proposed a partially heritable and unitary trait disposition toward social deviance in general, which they called "d," 
in the spirit of Spearman's "g." This common factor was proposed to account for the genetic covariance between sexual motivation, including adolescent promiscuity, and antisocial motivation, including an array of twenty-five delinquent acts "from drug abuse to vandalism" (p. 60). One of the two competing explanations advanced for the existence of this factor was indeed reproductive life history strategy. That view had also previously been proposed by Ellis (1987), who supported the utility of the $\mathrm{r}-\mathrm{K}$ concept in explaining why race and socioeconomic status are correlated with criminal behavior. In a subsequent study, Rowe and Flannery (1994) created a predictive latent variable called "delinquency proneness" that loaded positively and saliently on impulsivity, deceitfulness, rebelliousness, and peer delinquency, but also loaded negatively and saliently on mother affection, father affection, value placed on academic achievement, and parental encouragement of achievement. These latter four negative loadings are additional theoretical links to LHT. Another direct link to LHT was provided by Rowe, Vazsonyi, and Figueredo (1997), who found that juvenile delinquency was significantly correlated to mating effort both within individuals and across siblings. In this study, social failure was not able to account for the covariation between mating effort and delinquency. Again, heritable individual differences in life history strategy were offered as one possible explanation of these effects.

\section{POTENTIAL THEORETICAL CONTRIBUTIONS OF EVOLUTIONARY PSYCHOLOGY TO BEHAVIORAL GENETICS}

At the dawn of the "postgenomic era," it has been commonly recognized that there is a need for both bottom-up and top-down analyses from different areas (Goldsmith, Gernsbacher, Crabbe, Dawson, Gottesman, Hewitt, McGue, Pendersen, Plomin, Rose, and Swanson, 2003; Grant, 2003; Plomin and Crabbe, 2000; Plomin, Defries, Craig, and McGuffin, 2003). Geneticists can pursue the pathway by tracing a gene to its proteins, while psychologists and others attempt to follow the pathway down from large scale traits such as behaviors or behavior patterns, and, at some point in the future, the two sides will meet in the brain to complete the pathway (Plomin and Crabbe, 2000; Plomin et al., 2003). While the promise of functional genomics is a powerful lure for many geneticists, a topdown, behavior-centered approach is a much more accessible means to investigate genetic causes for psychologists in general (Plomin and Crabbe, 2000). While early genetic studies focused on finding one-to-one genotype-phenotype correlations, more recent work has seen a need to expand analyses to account for both the polygenic nature of most complex traits and the pleiotropic nature of many genes (Plomin and Rutter, 1998). There has been a recognized need to look to multiple genetic markers to account for more significant amounts of variance in behavioral studies (Grant, 2003; Keri, 2003; Luciano, Wright, Smith, Geffen, Geffen, and Martin, 2003; Risch, 2000; Rowe, 2003). Also, a single gene or small set of genes can influence multiple traits (Goldsmith et al., 2003; Luciano et al., 2003). The new picture of the future of behavioral genetics is not that of a breakthrough discovery of a single polymorphism which is responsible for some pathology or behavior, but that of a complex web of interacting genetic effects produces an array of related behaviors. 
While the need to incorporate this new understanding of behavioral genetics has been acknowledged (Plomin and Rutter, 1998; Plomin et al., 2003; Risch, 2000; Rowe, 2003), as yet much of the research has been of the bottom-up nature or protonomic. We hope that, by adding a theory-driven, top-down, behaviorcentered analysis to the discussion on human behavior and personality, we can inspire greater cross-disciplinary approaches.

Bouchard and Loehlin (2001) state that we know personality is largely influenced by genes but that we do not yet understand why this is, or should be, the case. They suggest new understanding can be gained by putting the study of behavior genetics of personality within the context of evolutionary psychology. Other avenues that will lead to a better understanding of the genetics underlying personality are better methodologies, including using large samples and using modern multivariate techniques (Bouchard and Loehlin, 2001). In general, an evolutionary psychological approach, in conjunction with a behavioral genetic approach, will contribute to the science of understanding the mechanisms underlying personality (Bouchard, 1995). Thus, behavioral genetics can make great contributions to evolutionary behavioral science, and evolutionary theory, especially LHT, can make great contributions to behavioral genetics (Bailey, 1998; Figueredo, 2000).

In that spirit, we propose to use a specific evolutionary theory, reproductive life history theory, to predict and test the existence of a relatively large positive manifold, or cluster, of genetic correlations. Multivariate behavioral genetic techniques have reached a high degree of sophistication in recent years, but the ap- plication of these methods is limited by the lack of a priori theory as to where and when to expect genetic correlations to evolve. LHT thus provides one source of theoretical guidance for the construction of theoretically-specified multivariate genetic models (Figueredo, 2000).

\section{Methods}

Sample. Data were generated in the MIDUS survey from a representative national sample and approximately 50,000 households were screened. Information was obtained from adult singletons, twins, and siblings and participants were between the ages of 25 and 74 . Although twin participants provided the same information as other participants included in the MIDUS database, they were solicited through an independent national survey. Of the twins contacted, constituting 14.8 percent of the 50,000 screened participants, 60 percent agreed to participate in the study. They also provided additional information that was particularly relevant to the study of twins, including information about their similarity in appearance, their birth, and their relationship with their co-twin. The zygosity of the twins was determined by self-report using indicators such as similarity in appearance and how often the twins' identity was confused during childhood (for procedural details see Johnson and Krueger, 2004). The present analyses used the data from 309 dizygotic (DZ) twins and 333 monozygotic (MZ) twins who had been reared together for at least the first 12 years of life, who were currently parents, and who had complete data on all the scales that were constructed. Only same-sex DZ twins were included in the genetic factor models for maximal comparability to the data from necessarily same-sex MZ twins. 
A secondary analysis of these data is useful because it contains a nationally representative sample of middle-aged adults. Such samples are relatively rare in evolutionary psychological research, which typically use convenience samples of young adult college undergraduates. Middle-aged adults in the United States, however, have had a greater chance to pick their life niches, to marry (or not), to bear and raise offspring (or not), and to create social networks within the communities in which they have chosen to live. Middle-aged adults therefore constitute a better sample on which to test long-term effects of hypothesized psychological adaptations for life history strategy.

Procedures. Original items from the MIDUS questionnaire were selected and constructed into theoretically meaningful measures. Some of these measures are identical to MIDUS scales, some are a combination of MIDUS scales, and some are newly constructed scales. The original metrics in which all items were measured were Likert scales (e.g., from 1 to 5). Because a value of 1 was sometimes the highest value and other times the lowest value verbal response option in the original items, we reversed many of these Likert scales so that the highest number (e.g., 5) always represented the highest degree of semantic endorsement. We then standardized the original Likert scales to construct coherent measures from items with potentially different numbers of response options. We report the internal consistencies of the constructed measures as calculated by Cronbach's alpha. A full listing of the MIDUS items used is available from the authors upon request.

We note here that the MIDUS main (singleton) sample contained 2,141 items.
In our analyses, we used 181 items for indicators of life history strategy, 48 items for indicators of Covitality, and 24 variables for indicators of Personality. This totaled 253 items, organized into 30 scales, out of the over 2,000 items available in the MIDUS survey as a whole, which is fewer than 12 percent of the items available. This focused attention involved careful theoretical selection of items, construction of scales, and specification of the factor models.

Items were selected based on the consensus of all four of the present authors that they were probable indicators of the hypothetical constructs under study. Thus, although the MIDUS survey was not specifically designed to test evolutionary hypotheses, we selected only the items and scales that were theoretically relevant for our purposes. It is important to note that we do not claim that the $\mathrm{K}$-Factor explains everything either in the MIDUS data or elsewhere, but instead is limited to a specific and circumscribed set of hypothesized indicators, which were included in the models. Sometimes, scales constructed by the original MIDUS researchers were deemed appropriate for our purposes; other times we recombined the items into alternate scales that were both coherent and more relevant to evolutionary theory.

The theoretical criteria were as follows. For convergent indicators of life history strategy, we selected items that measured three broad facets that life history theory predicts will constitute complementary aspects of a coherent, unitary factor. The first facet was Personal Function. These characteristics included cognitive and behavioral indicators of individual traits such as long-term thinking and reflective, deliberate, and thoughtful 
attitudes toward the past, present, and future indicative of high-K personal strategies. The second facet was Familial Function. As before, these characteristics, which included cognitive and behavioral indicators of parental and nepotistic effort, including quality relationships with one's own parents, one's romantic partner, one's own children, and one's extended kin, in the capacity of both giving and receiving altruistic benefits, indicate high-K familial strategies. The third facet was Social Function, which included cognitive and behavioral indicators of reciprocal altruism, including cooperative relationships with friends and associates in the broader community and social institutions, again in the capacity of both giving and receiving, indicating high- $K$ social strategies.

For the convergent indicators of Covitality, we selected indicators of general physical and mental health, whether positive or negative, including subjective well-being, positive and negative affect, general health, and biomedical symptoms. For the convergent indicators of Personality, we selected indicators of the Big Five factors of personality, Openness to Experience, Conscientiousness, Extraversion, Agreeableness, and Neuroticism, exactly as specified in the original scoring of the MIDUS survey. We used each of these scales as indicators in the factor models.

\section{BEHAVIORAL INDICATORS OF LifE History STRATEGy}

Mother Relationship Quality. Mother Relationship Quality is defined by the estimated time, support, and love an individual perceived to have received from his/her mother while growing up. These items did not specify whether the mother was a biological parent or stepparent. Our scale is a combination of the MIDUS Maternal Affection Scale and Maternal Discipline Scale. There were a total of 12 items used in this scale. Sample questions were, "How much love and affection did she give you?" and "How would you rate your relationship with your mother (or the woman who raised you) during the years you were growing up?" Cronbach's alpha was 0.83 .

Father Relationship Quality. Father Relationship Quality is defined by the estimated time, support, and love an individual perceived to have received from his/her father while growing up. These items did not specify whether the father was a biological parent or stepparent. Our scale is combination of the MIDUS Paternal Affection Scale and Paternal Discipline Scale. There were a total of 12 items used in this scale. Sample questions were, "How much did he understand your problems and worries?" and "How strict was he with his rules for you?" Cronbach's alpha was 0.87 .

Marital Relationship Quality. This scale measured the past, current, and predicted future general marital quality perceived by the individual. Marital quality was operationalized by such items such as how the couple makes decisions, activities done together, and emotional closeness. Our scale combines the MIDUS Spouse/Partner Disagreement Scale, Spouse/Partner Support Scale, Spouse/Partner Strain Scale, and Spouse/ Partner Decision Making Scale. Additional items relating to relationships and an item from the MIDUS Life Satisfaction Scale were also added. There were a total of 31 items in this scale. Questions included, "How would you rate your marriage or close relationship these days?" 
and "My partner and I are a team when it comes to making decisions." Cronbach's alpha was 0.95 .

Children Relationship Quality. Children Relationship Quality was measured by the general perception of one's relationship with his/her children. The scale is composed of child related items including one item from the MIDUS Perceived Inequality in Family Scale and one from Life Satisfaction Scale. There were a total of 5 items on this scale. An example is, "How would you rate your overall relationship with your children these days?" Cronbach's alpha was 0.81 .

Family Support. Family Support was measured by the estimated financial or emotional support one perceives to receive from family members other than a partner or spouse. This scale is composed of the MIDUS Family Support Scale and a few additional items. There were 6 items on this scale. Sample questions include, "How much can you rely on them [family] for help if you have a serious problem?" and "On average, about how many hours per month do you receive informal emotional support from your children or grandchildren?" Cronbach's alpha was 0.74 .

Altruism Towards Kin. Altruism is defined as concern about and contributing to the well-being of others. This scale contains the kin related items from the MIDUS Normative Primary Obligation Scale and one item from the Provide Emotional Support Scale. There were 5 items on this scale. Sample items are, "How much obligation would you feel to call, write, or visit your adult children on a regular basis?" and "How much obligation would you feel to call your parents on a regular basis?" Cronbach's alpha was 0.65 .

Friends Support. Friends Support was measured by the estimated financial or emotional support one perceives to receive from friends other than one's partner or spouse. This scale is composed of a sample of items from the MIDUS Friend Support Scale and the Friend Strain Scale. There were a total of 5 items on this scale. An example is, "How much can you open up to them [your friends] if you need to talk about your worries?" Cronbach's alpha was 0.84 .

Altruism Towards Non-Kin. This scale is composed of the non-kin related items from the MIDUS Family Obligation, Civil Obligation, Work Obligation, Altruism, Provide Financial Support, Normative Primary Obligation, Loyola Generativity, and Provide Emotional Support Scales. There were 35 items on this scale. Sample questions include, "How much thought and effort do you put into your contribution to the welfare and wellbeing of other people these days?" and "How much obligation would you feel to volunteer time or money to social causes you support?" Cronbach's alpha was 0.86 .

Close Relationships. Two items from the MIDUS Positive Relations with Others Scale comprised the Close Relationships Scale. These items were, "Maintaining close relationships has been difficult and frustrating for me," and "I have not experienced many warm and trusting relationships with others." Cronbach's alpha was 0.71 .

Communitarian Beliefs. Communitarian Beliefs are the beliefs one holds about the general nature of society and other people. This scale is composed of the MIDUS Meaningfulness of Society, Social Integration, Acceptance of Others, and Social Actualization Scales, and two items from the Social Contribution Scales. There were 14 items on this scale. Examples of items include, "People who 
do a favor expect nothing in return," and "The world is becoming a better place for everyone." Cronbach's alpha was 0.70 .

Religiosity. Religiosity was defined by the estimated time, energy, and financial resources one contributed to religious or spiritual causes and by the generally perceived emotional commitment to a religion. This scale is composed of the MIDUS Religious/Spiritual Coping, Spirituality, Religious Identification Scales, religiosity relevant items from the $\mathrm{Re}$ ceive Instrumental Support from Other Sources, Provide Financial Support, and Receive Financial Support Scales, and other religiosity-relevant items not included in MIDUS scales. There were a total of 17 items on this scale. Examples of items are, "How important is religion in your life?" and "In a typical month, about how many times do you attend religious services?" Cronbach's alpha was 0.90 .

Financial Status. Financial Status was measured by estimates of one's perceived financial situation. This scale was not part of an existing MIDUS scale. There were a total of 6 items. Examples are "How would you rate your financial situation these days?" and "How would you rate the amount of control you have over your financial situation these days?" Cronbach's alpha was 0.69 .

Health Control. Health Control is conceptualized as an estimate of the control one has over their own health. This scale was not part of an existing MIDUS scale. There were a total of 6 items used in this scale. Two examples are, "Keeping healthy depends on the things I can do," and "How much thought and effort do you put into your health these days?" Cronbach's alpha was 0.69 .

Agency. Agency is an estimate of personal confidence and assertiveness. The scale is identical to the MIDUS Agency Scale. There were 5 items on this scale. These items were, "Please indicate how well each of the following describes you: self-confident, forceful, assertive, outspoken, dominant." Cronbach's alpha was 0.80 .

Advice Seeking. Advice Seeking is the estimated frequency with which an individual actively seeks advice from others for the purpose of making a decision. The scale is identical to the MIDUS Advice Seeking Scale. There were a total of 3 items on this scale. For example, "I like to get advice from others before making a decision." Cronbach's alpha was 0.58 .

Foresight and Anticipation. The Foresight and Anticipation scale estimated how much someone can predict, given present circumstances, what will happen in the future. The scale is identical to the MIDUS Foresight and Anticipation Scale. There were a total of 4 items on this scale. An example of the questions is: "I am good at figuring out how things will turn out." Cronbach's alpha was 0.78 .

Insight into Past. Insight into Past estimated how much one considered events that have happened in the past in order to understand current circumstances. The scale is identical to the MIDUS Insight into Past Scale. There were a total of 4 items in this. For example, "Making sense of my past helps me figure out what to do in the future." Cronbach's alpha was 0.67 .

Primary Control/Persistence. Primary Control/Persistence estimated how much one attempts to triumph in the face of adversity. That is, how persistent is one in solving problems. The scale is identical to the MIDUS Primary Control Scale. There were 5 items in this scale. Sample questions include, "When faced with a bad situation, I do what I can to change it 
for the better," and "When I encounter problems, I don't give up until I solve them." Cronbach's alpha was 0.75 .

Flexible/Positive Reappraisal. Flexible/ Positive Reappraisal estimated how well someone can make the best of a bad situation. The scale is identical to the MIDUS Secondary Control Scale. There were 4 items on this scale. An example question is, "Even when everything seems to be going wrong, I can usually find a bright side to the situation." Cronbach's alpha was 0.80 .

Self Directedness/Planning. Self Directedness/Planning estimated how much one plans for the future. The scale is identical to the MIDUS Self Directedness and Planning Scale. There were 3 items on this scale. One question was, "I find it helpful to set goals for the near future." Cronbach's alpha was 0.75 .

\section{Behavioral INDICATORS OF COVITALITY}

Subjective Well-Being. Subjective WellBeing estimated one's general satisfaction with themselves and their life. Our scale has one item from the MIDUS Life Satisfaction Scale and two additional items not in any MIDUS Scale. There were 3 items on this scale. A sample question is, "Overall, how satisfied are you with yourself?" Cronbach's alpha was 0.72 .

Negative Affect. Negative Affect estimated how sad or worthless one generally felt. The scale is identical to the MIDUS Negative Affect Scale. There were a total of 6 items on this scale. A sample question is, "During the past 30 days, how much of the time did you feel hopeless?" Cronbach's alpha was 0.88 .

Positive Affect. Positive Affect estimated how generally happy or worthwhile one felt. The scale is identical to the MIDUS Positive Affect Scale. There were a total of 6 items on this scale. Sample questions include, "During the past 30 days, how much of the time did you feel extremely happy?" and "During the past 30 days, how much of the time did you feel full of life?" Cronbach's alpha was 0.91 .

General Health. General Health estimated one's report of their overall physical and mental health. The scale contains items from the MIDUS Life Satisfaction Scale. There were a total of 5 items. Sample questions include, "In general, would you say your physical health is ..." and "In general, compared to most (men/ women) your age, how would you say your health is?" Cronbach's alpha was 0.70 .

Medical Symptoms. Medical Symptoms were estimated by the endorsement of 29 possible medical conditions. The scale was not part of any existing MIDUS scale. Examples include the endorsement of items, such as, "Thyroid disease," "High blood pressure or hypertension," or "Ulcer." Cronbach's alpha was 0.66 .

\section{INDICATORS OF PERSONALITY}

Openness to Experience. The personality trait Openness to Experience estimated the degree to which individuals endorsed six statements. The scale contains six of the seven items from the MIDUS Openness to Experience Scale. Directions were as follows "Please indicate how well each of the following describes you: Creative, Imaginative, Intelligent, Curious, Broad-minded, Sophisticated." Cronbach's alpha was 0.74 .

Conscientiousness. The personality trait Conscientiousness estimated the degree to which individuals endorsed four statements. The scale is identical to the MIDUS Conscientiousness Scale. The characteristics were rated on a four-point 
scale and are as follows, "Please indicate how well each of the following describes you: Organized, Responsible, Hardworking, Careless." Cronbach's alpha was 0.58 .

Extraversion. The personality trait Extraversion estimated the degree to which individuals endorsed five statements. The scale is identical to the MIDUS Extraversion Scale. Directions were as follows: "Please indicate how well each of the following describes you: Outgoing, Friendly, Lively, Active, Talkative." Cronbach's alpha was 0.78 .

Agreeableness. The personality trait Agreeableness estimated the degree to which individuals endorsed five statements. The scale is identical to the MIDUS Agreeableness Scale. Directions were as follows: "Please indicate how well each of the following describes you: Helpful, Warm, Caring, Softhearted, Sympathetic." Cronbach's alpha was 0.81 .

Neuroticism. The personality trait Neuroticism estimated the degree to which individuals endorsed four statements. The scale is identical to the MIDUS Neuroticism Scale. Directions were as follows: "Please indicate how well each of the following describes you: Moody, Worrying, Nervous, Calm." Cronbach's alpha was 0.75 .

\section{Statistical Analyses}

All statistical analyses used SAS version 8.2 (SAS Institute, 1999). The phenotypic factor models were constructed the same way as for the singleton data (Figueredo, Vásquez, Brumbach, and Schneider, in press), at first ignoring the fact that the respondents were twins. For behavioral genetic analyses, each pair of twins was double entered into the file, meaning that each member of the pair was entered once as a proband and once as a cotwin (McGue, 1992). The Falconer (1989) formula was applied for estimating both univariate and bivariate heritabilities:

$$
h^{2}=2\left(r_{M Z}-r_{D Z}\right)
$$

This equation essentially states that heritabilities $\left(h^{2}\right)$ can be estimated as equal to twice the difference between the monozygotic $\left(\mathrm{r}_{M Z}\right)$ and dizygotic $\left(\mathrm{r}_{D Z}\right)$ twin correlations. The univariate heritabilities are estimated using correlations across twins for the same traits; the bivariate heritabilities are estimated using the correlations both across twins and across traits. This method can thus be used to generate all the elements of a genetic variance-covariance matrix.

The genetic variance-covariance matrix obtained was then subjected to factor modeling. Factor analyses were performed using PROC FACTOR. For the phenotypic factor models, initial communalities were estimated using squared multiple correlations and principal axis estimation for maximum comparability to the singleton model. For the genetic factor models, the principal components model was used, setting all prior communalities to unity. Because the Falconer formula calculates components of covariance across two independent samples (MZ and DZ twin correlations), the univariate and bivariate heritabilities (genetic variances and covariances) were presumed to be relatively free of sampling error and other random sources of variance (see McCrae et al., 2001, for a similar application of the principal components model to genetic correlations). Subjective scree plots and proportions of variance accounted for were used to determine the optimal number of factors to be retained. 
All Cronbach's alphas and bivariate correlations were performed using PROC $C O R R$. General linear models were performed using PROC GLM.

\section{Results}

Descriptive Statistics. The following descriptive statistics apply to the combined sample of monozygotic and same-sex dizygotic twins. The sample was 43.4 percent and 56.6 percent female. Ages ranged from 25 to 74 years of age, with a mean of 44.7. The racial breakdown was 91.4 percent White, 4.4 percent Black or AfricanAmerican, 0.6 percent Native-American or Aleutian Islander/Eskimo, 0.3 percent Multiracial, 1.0 percent Other, and 2.3 percent Missing. Both personal and spousal annual income brackets ranged from less than zero (net loss) to $\$ 100,000-\$ 149,999$, with a modal income bracket of $\$ 20,000$ $\$ 24,999$ for those who made any annual income at all. Both personal and spousal highest educational level achieved ranged from no school/some grade school to $\mathrm{PhD} / \mathrm{EdD} / \mathrm{MD} / \mathrm{DDS} / \mathrm{LLD} / \mathrm{LLB} / \mathrm{JD} /$ Other Professional, with a modal highest educational level of High School Graduate.

\section{Life History Theory: Phenotypic Fac-} tor Models. We used 20 scales constructed from MIDUS items hypothesized to be indicators of the K-Factor. Factor analysis revealed that this single common factor that explained 72 percent of the reliable variance in these measures. Table 1 displays the convergent validities (factor pattern) of each of these measures in relation to the $\mathrm{K}$-Factor. The factor loadings tended to be of moderate magnitude, ranging mostly between 0.40 and 0.60 , indicating a reasonable degree of convergence among all the hypothesized indicators. Furthermore, all the factor loadings were positive in direction, as initially hypothesized. All the cog- nitive and behavioral indicators of life history included in the model therefore cluster as predicted, indicating a coherent and coordinated life history strategy.

Because life history theory predicts that high-K individuals will manifest greater phenotypic (as opposed to genotypic) fitness of organisms, high- $K$ individuals should be more individually viable on a variety of indicators of general health, developmental stability, and mental and physical function than low- $\mathrm{K}$ individuals. With these predictions in hand, we constructed another common factor, the "Covitality" Factor (Weiss, King, and Enns, 2002), from 5 MIDUS scales to measure these predicted effects of increased Somatic Effort expended and Parental and Nepotistic Effort received during development. Table 2 displays the factor pattern for this additional construct. The factor loadings tended to be of moderate to high magnitude, ranging mostly between 0.50 and 0.70 in absolute value, indicating a fairly good degree of convergence among all the hypothesized indicators. Furthermore, the directionalities of all these loadings were exactly as hypothesized. All the physical and mental indicators of general health included in the model therefore cluster as predicted, indicating a unitary construct of "Covitality."

Furthermore, Fitness Indicator Theory (Miller, 2000) predicts that increased " $\mathrm{Co}$ vitality" should also be behaviorally displayed in the manifestation of sexuallyselected mental traits. We therefore performed a factor analysis on the MIDUS scales for the "Big Five" personality factors to obtain a higher-order personality construct, perhaps reflecting the perceived characteristics of a high-mate-value or "ideal" romantic partner (Figueredo, Sefcek, and Jones, in press), which is displayed in Table 3. The factor loadings 
TABLE 1

Factor Pattern (Standardized Regression Coefficients) for the Phenotypic K-Factor

\begin{tabular}{lclc}
\hline \hline MidUS SCALE & K-FACTOR LoAding & MIDUS Scale & K-FACror LOAdING \\
\hline Mother Relationship Quality & 0.41 & Religiosity & 0.28 \\
Father Relationship Quality & 0.38 & Financial Status & 0.42 \\
Marital Relationship Quality & 0.42 & Health Contro & 0.38 \\
Children Relationship Quality & 0.44 & Agency & 0.40 \\
Family Support & 0.51 & Advice Seeking & 0.25 \\
Altruism Towards Kin & 0.39 & Foresight/Anticipation & 0.49 \\
Friends Support & 0.55 & Insight Into Past & 0.44 \\
Altruism Towards Non-Kin & 0.64 & Primary Control/Persistence & 0.60 \\
Close Relationship Quality & 0.50 & Flexible/Positive Reappraisal & 0.62 \\
Communitarian Beliefs & 0.52 & Self-Directedness/Planning & 0.62 \\
\hline
\end{tabular}

TABLE 2

Factor Pattern (Standardized Regression Coefficients) For the PhenotyPiC COVITALITY FACTOR

\begin{tabular}{lc}
\hline \hline MIDUS SCale & CovitalitY Loading \\
\hline Subjective Well-Being & 0.62 \\
Negative Affect & -0.73 \\
Positive Affect & 0.74 \\
General Health & 0.50 \\
Medical Symptoms & -0.46 \\
\hline
\end{tabular}

tended to be of moderate to high magnitude, ranging mostly between 0.30 and 0.70 in absolute value, indicating a fairly good degree of convergence among all the hypothesized indicators. Furthermore, the directionalities of all these loadings were exactly as hypothesized, with only Neuroticism loading negatively on the factor. All the personality factors included in the model therefore cluster as predicted, indicating a general personality profile associated with life history.

The bivariate correlations between the K-Factor, the Covitality Factor, and this general Personality Factor are displayed in Table 4. All of these correlations are statistically significant and positive, supporting both the magnitudes and directions of the associations among these factors that were originally hypothesized.
TABLE 3

Factor Pattern (Standardized Regression Coefficients) For the Phenotypic PERSONALITY FACTOR

\begin{tabular}{lc}
\hline \hline Midus Scale & Personaltry Loaming \\
\hline Openness To Experience & 0.61 \\
Conscientiousness & 0.48 \\
Extraversion & 0.73 \\
Agreeableness & 0.62 \\
Neuroticism & -0.29 \\
\hline
\end{tabular}

To determine whether the Covitality Factor and this general Personality Factor were extended indicators of Life History Strategy, as suggested by both theory and the previous results (Figueredo, Vásquez, Brumbach, and Schneider, in press), we factor analyzed them along with the K-Factor. We obtained a single higherorder factor, which we called the "SuperK" Factor, which explained virtually all of the reliable variance among them. The factor pattern for this Super-K Factor is shown in Table 5. The higher-order factor loadings were all relatively high in magnitude, ranging mostly from 0.60 to 0.80 , indicating a very good degree of convergence among all the hypothesized indicators. Furthermore, the directionalities of these loadings were all positive as hypothesized. This finding supports the 
TABLE 4

Bivariate Correlations Among Phenotypic K-Factor, Covitality Factor, and PERSONALITY FACTOR

\begin{tabular}{lccc}
\hline \hline MIDUS FaCtor & K-FACTOR & Covitalitr & Personalitr \\
\hline K-Factor & 1.00 & & \\
Covitality Factor & 0.54 & 1.00 & \\
Personality Factor & 0.69 & 0.43 & 1.00 \\
\hline
\end{tabular}

TABLE 5

Factor Pattern (Standardized Regression COEFFICIENTS) FOR THE PHENOTYPIC SUPER-K FACTOR

\begin{tabular}{lc}
\hline \hline MIDUS FACTOR & SUPER-K FACTOR LOADING \\
\hline K-Factor & 0.82 \\
Covitality Factor & 0.60 \\
Personality Factor & 0.75 \\
\hline
\end{tabular}

hypothesis that a high-K Life History Strategy predicts the physical and mental health consequences of high somatic effort expended and high parental and nepotistic effort received and is also manifested in the behavioral display of sexually-selected mental traits. All of the model parameters for the twin data were virtually identical to those obtained using the singleton data.

\section{Social Privilege Theory: An Alterna-} tive Hypothesis. Life history and social and familial traits correlate significantly. Hence, it is important to address "Social Privilege Theory" (Gottfredson, in press) as an alternative hypothesis for both the existence of and the associations among these clusters of life history traits. Social privilege theory is a sociological view that sociocultural factors such as sex, race, and class determine characteristics, such as mental abilities and health status, normally attributed by differential psychologists to individual differences (Arrow, Bowles, and Durlauf, 2000; Gottfredson, in press; Kawachi, Kennedy, and Wilkinson, 1999; Kerckhoff, 2000;
Wilkinson, 1996). For example, the "Family Advantages" version of social privilege theory maintains that more or less advantaged families transmit social class advantages and disadvantages by providing greater or lesser opportunities during development. Advocates of this view predict that equalizing social opportunities will dissolve the observed links between parent and child outcomes. To control for the possible effects of social stratification, hierarchical regression models were used to residualize (statistically adjust) all of the 30 targeted life history traits on respondent sex, race, total financial earnings of the self, spouse, and all other family members for the past 12 months, and the highest degree of education achieved to date by both the self and spouse. With this done, we repeated the entire series of factor analyses reported above on these residualized variables.

Although virtually every multiple regression model was statistically significant for this set of socioeconomic and demographic predictors, the amount of variance collectively accounted for by each entire regression model was always less than 10 percent and usually much less than that. Furthermore, the factor loadings for the K-Factor, the Covitality Factor, and the Personality Factor on the residualized lifehistory traits were not appreciably attenuated by this statistical manipulation, nor were either the correlations among them or with the higher-order Super-K Factor. In fact, the factor model parameters were vir- 
TABLE 6

Heritabilities and Genetic Factor Loadings For the IndiCators of the Genetic K-FaCtor

\begin{tabular}{lcc}
\hline \hline MIDUS Scale & HeRITABILITY $\left(h^{2}\right)$ & Genetic K-Factor Loading \\
\hline Mother Relationship Quality & 0.42 & 0.88 \\
Father Relationship Quality & 0.51 & 0.67 \\
Marital Relationship Quality & 0.42 & 0.61 \\
Children Relationship Quality & 0.12 & 0.91 \\
Family Support & 0.37 & 0.89 \\
Altruism Towards Kin & 0.13 & 0.75 \\
Friends Support & 0.31 & 0.85 \\
Altruism Towards Non-Kin & 0.33 & 0.88 \\
Close Relationship Quality & 0.34 & 0.82 \\
Communitarian Beliefs & 0.33 & 0.99 \\
Religiosity & 0.37 & 0.50 \\
Financial Status & 0.12 & 0.74 \\
Health Control & 0.03 & - \\
Agency & 0.41 & 0.75 \\
Advice Seeking & 0.14 & 0.04 \\
Foresight/Anticipation & 0.55 & 0.68 \\
Insight Into Past & 0.10 & 0.76 \\
Primary Control/Persistence & 0.43 & 0.97 \\
Flexible/Positive Reappraisal & 0.65 & 0.75 \\
Self-Directedness/Planning & 0.39 & 0.77 \\
\hline
\end{tabular}

tually unchanged. In summary, Social Privilege Theory cannot explain either the K-Factor itself or any of the additional correlations with Covitality and Personality that constitute the Super-K Factor.

\section{Life History Theory: Genetic Factor}

Models. Generally, the heritability estimates of the individual scales were substantial but those for the genetic common factors were appreciably greater. Moreover, the genetic factor loadings were generally greater than the phenotypic factor loadings. Table 6 displays the heritabilities $\left(h^{2}\right)$ and genetic factor loadings obtained for the indicators of the Genetic K-Factor, sensu stricto, which accounted for 61 percent of the variance of its component scales. With a few exceptions, the heritabilities were moderate, mostly ranging in magnitude between 0.30 and 0.50 ; with some of those same exceptions, the genetic factor loadings were relatively high, mostly ranging in magnitude be- tween 0.60 and 0.90 , and positive in direction. The latter finding suggests that the phenotypic correlations observed among cognitive and behavioral life history traits are primarily genetic in origin and influenced by a common set of genes.

Table 7 displays the heritabilities $\left(h^{2}\right)$ and genetic factor loadings obtained for the indicators of the Genetic Covitality Factor, which accounted for 85 percent of the variance of its component scales. Again, the heritabilities were moderate, mostly ranging in magnitude between 0.30 and 0.40 ; the genetic factor loadings were very high, mostly ranging in magnitude between 0.90 and 1.0 in absolute value, and in the directions hypothesized. Again, the latter finding suggests that the phenotypic correlations observed among indicators of physical and mental wellbeing are also primarily genetic in origin and influenced by a common set of genes.

Table 8 displays the heritabilities $\left(h^{2}\right)$ and genetic factor loadings obtained for 
TABLE 7

Heritabilities and Genetic Factor LoAdings For the Indicators of the Genetic Covitality FaCtor

\begin{tabular}{lcc}
\hline \hline MIDUS Scale & Heritability $\left(h^{2}\right)$ & Genetic Covitality Loading \\
\hline Subjective Well-Being & 0.41 & 0.91 \\
Negative Affect & 0.35 & -0.92 \\
Positive Affect & 0.46 & 0.89 \\
General Health & 0.21 & 1.05 \\
Medical Symptoms & 0.33 & -0.89 \\
\hline
\end{tabular}

TABLE 8

Heritabilities and Genetic Factor Loadings for the Indicators of the Genetic Personality Factor

\begin{tabular}{lcc}
\hline \hline Midus Scale & Heritability $\left(h^{2}\right)$ & Genetic Personality Loading \\
\hline Openness To Experience & 0.39 & 0.67 \\
Conscientiousness & 0.40 & 0.70 \\
Extraversion & 0.69 & 0.91 \\
Agreeableness & 0.55 & 0.83 \\
Neuroticism & 0.52 & -0.38 \\
\hline
\end{tabular}

the indicators of the Genetic Personality Factor, which accounted for 55 percent of the variance of its component scales. Again, the heritabilities were moderate, mostly ranging in magnitude between 0.40 and 0.60 ; the genetic factor loadings were generally high, mostly ranging in magnitude between 0.40 and 0.90 in absolute value, and in the directions hypothesized. The latter finding suggests that the phenotypic correlations observed among the major personality factors are also primarily genetic in origin and influenced by a common set of genes.

Table 9 displays the significant and high genetic correlations among the K-Factor, the Covitality Factor, and the Personality Factor. All of these genetic correlations were statistically significant and positive, supporting both the magnitudes and directions of the associations among these factors that were originally hypothesized.

Table 10 displays the heritabilities $\left(h^{2}\right)$ and genetic factor loadings obtained for the indicators of the Genetic Super-K Factor, which accounted for 82 percent of the variance of its component scales. The heritabilities were moderate to high, ranging in magnitude between 0.50 and 0.70 ; the genetic factor loadings were high, ranging in magnitude between 0.80 and 0.95 , and in the positive directions hypothesized. The latter finding suggests that the phenotypic correlations observed among the three major life history factors identified are primarily genetic in origin and influenced by a common set of genes. The estimated heritability of the Genetic Super-K Factor as a whole was 0.68 .

Only two of the MIDUS scales tested failed to have salient loadings on the genetic K-Factor, Health Control and Advice Seeking. Health Control had a negative Falconer estimate of heritability, which was virtually equal to zero, and therefore could not be included in the factor model. Advice Seeking had a positive but very low heritability and was esti- 
TABLE 9

Bivariate Genetic Correlations Among the K-Factor, Covitality Factor, AND PERSONALITY FACTOR

\begin{tabular}{lccc}
\hline \hline Midus Factor & Genetic K-Factor & Genetic Covitality & Genetic Personal.JTY \\
\hline Genetic K-Factor & 1.00 & & \\
Genetic Covitality Factor & 0.69 & 1.00 & \\
Genetic Personality Factor & 0.78 & 0.70 & 1.00 \\
\hline
\end{tabular}

TABLE 10

Heritabilities and Genetic Factor Loadings for the K-Factor, Covitality, and Personality Factor

\begin{tabular}{lcc}
\hline \hline MIdUS Factor & HeritablutY $\left(h^{2}\right)$ & Genetic SUPER-K Loading \\
\hline Genetic K-Factor & 0.65 & 0.92 \\
Genetic Covitality Factor & 0.52 & 0.86 \\
Genetic Personality Factor & 0.59 & 0.92 \\
\hline
\end{tabular}

mated as having a negligibly small genetic factor loading on the K-Factor. All of the MIDUS scales comprising the Genetic Covitality and Personality Factors had positive (non-zero) heritabilities and salient genetic factor loadings, although some of these factor loadings were in the expected negative direction. General Health had a slightly out-of-range Falconer estimate of heritability, which was virtually equal to one. A nearly-perfect genetic factor loading for General Health on the Covitality Factor, however, is not very surprising.

Effects of Shared Environment. The Falconer (1989) formula estimates shared environmental effects $\left(c^{2}\right)$ as equal to the difference between twice the dizygotic $\left(r_{D Z}\right)$ twin correlations and the monozygotic $\left(r_{M Z}\right)$ twin correlations. Because the shared environmental components of the individual indicators are of little interest, we present only those of the major common factors identified. The monozygotic $\left(r_{M Z}\right)$ twin correlations were 0.60 for the K-Factor, 0.52 for the Covitality Factor,
0.48 for the Personality Factor, and 0.56 for the Super-K Factor; the dizygotic $\left(r_{D Z}\right)$ twin correlations were 0.27 for the K-Factor, 0.26 for the Covitality Factor, 0.18 for the Personality Factor, and 0.22 for the Super-K Factor. Thus, the shared environmental components were estimated at $-0.05,0.00,-0.11$, and -0.12 , respectively, for each of these factors. Because variance components cannot in reality assume negative values, we may interpret these small negative estimates as indicating shared environmental effects of virtually zero for all of these factors. This finding is very similar to the lack of shared environmental effects documented for many personality and individual difference factors (Rowe, 1994).

\section{DISCUSSION}

These results point to the existence of a single, highly heritable latent psychometric common factor (the K-Factor) that, as predicted by evolutionary ecological theory, underlies both the phenotypic and genetic covariances among a wide 
array of behavioral and cognitive life history traits. In addition, as in the previously obtained results (Figueredo, Vásquez, Brumbach, and Schneider, in press), the $\mathrm{K}$-Factor is significantly associated with a composite of both mental and physical health outcomes ("Covitality") and with a general factor derived from the "Big Five" dimensions of personality. Furthermore, these results indicate that a substantial portion of these phenotypic correlations are genetic in nature.

These results also suggest that the same set of pleiotropic genes influence each of the measured life history traits considerably. This finding supports the hypothesis that Life History Strategy is predominantly under the control of regulatory genes that coordinate the expression of an entire array of life history traits (cf., Bailey, 1998). Presumably, common genetic control is necessary to integrate these individual tactical elements into a coherent and internally consistent reproductive strategy.

The hypothesized existence of such higher-order regulatory genes, however, does not rule out adaptive interaction with the environment (cf., Belsky, 2000). It is quite probable that the expression of these regulatory genes is conditional, that is, subject to environmental triggers. Natural and sexual selection would presumably favor enough developmental plasticity in the control of Life History Strategy to respond to an array of adaptive contingencies that were reliably present in human evolutionary history. Our results are consistent with this assertion, indicating that a substantial portion of the variation in life history traits remains under environmental control.

Previously, a number of publications in the field of behavioral genetics have supported the position that many of what we are calling life history traits are both 1) heritable, and 2) genetically correlated. What we have presented evidence for in the current empirical study is that many of these genetically correlated traits are indeed part of an extensive positive manifold of genetically correlated life history traits. Hopefully, this more inclusive multivariate model will help provide an overarching theoretical framework for all the separately reported heritabilities and genetic covariances among a wide array of what appear to be life history traits. Furthermore, in much of the previous work, interpretations have been proposed that some of the observed correlations are attributable to sociological influences such as those proposed as causal factors by Social Privilege Theory. Our analyses, however, have shown that Social Privilege alone does not fully account for the observed covariances among life history traits.

As always, the nature of a latent common factor underlying any positive manifold of correlated traits is subject to interpretation. We have used reproductive life history strategy as the organizing theoretical principle to generate specific predictions as to precisely what traits we expect should be correlated. Alternative interpretations are always possible. However, we believe that this heuristic strategy has met with reasonable success in providing theoretical guidance for the construction of a multivariate behavioral genetic model of life history strategy, as predicted by Bailey (1998). We believe that we have made and confirmed predictions that might not be readily derivable from other theories. We therefore hope that this will constitute a contribution towards a productive integration between behavioral genetics and evolutionary psychology. 


\section{ACKNOWLEDGMENTS}

We wish to thank Linda Gottfredson for her helpful suggestions on the testing of Social Privilege Theory and permission to cite one of her manuscripts that is still in press. We also wish to thank Wendy Johnson for helpful comments on a previous version of this manuscript.

\section{REFERENCES}

Arrow, K., S. Bowles, and S, Durlauf, 2000. Meritocracy and economic inequality. Princeton: Princeton University Press.

BAlLEY, J. M. 1998. Can behavior genetics contribute to evolutionary behavioral science? In C. B. Crawford and D. Krebs (eds.), Handbook of Evolutionary Psychology: Ideas, Issues, and Applications, pp. 211-233. Mahwah, NJ: Lawrence Erlbaum Associates.

BELSKY, J. 2000. Conditional and alternative reproductive strategies: Individual differences in susceptibility to rearing experiences. In J. L. Rodgers, D. C. Rowe, and W. B. Miller (eds.), Genetic Influences on Human Fertility and Sexuality, pp. 127-146. Mahwah, NJ: Lawrence Erlbaum Associates.

Bouchard, T. J. 1993. Genetic and environmental influences on adult personality: Evaluating the evidence. In J. Hettema and I. J. Deary (eds.), Foundations of Personality, pp. 15-44. Netherlands: Kluwer Academic Publishers.

1995. Longitudinal studies of personality and intelligence: A behavior genetic and evolutionary psychology perspective. In D. H. Saklofske and M. Zeidner (eds.), International Handbook of Personality and Intelligence, pp. 81-106. New York: Plenum Press.

2004. Genetic influences on human psychological traits. Current Directions in Psychological Science 13(4): 148-151.

Bouchard, T. J., and J. C. Loehlin. 2001. Genes, evolution, and personality. Behavior Genetics 31(3):243-273.

Bouchard, T. J., M. MCGUE, D. LYKKEN, and A. Tellegen. 1999. Intrinsic and extrinsic religiousness: Genetic and environmental influences and personality correlates. Twin Research 2:88-98.

Bouchard, T. J., N. L. Segal, A. Tellegen, M. McGue, and R. Krueger. 2003. Evidence for the construct validity and heritability of the Wilson-Patterson conservatism scale: A rearedapart Iwins study of social attitudes. Personality and Individual Differences 34:959-969.

Bouchard, T. J., N. L. Segal, A. Tellegen, M. MCGue, M. Keyes, and R. Krueger. 2004. Genetic influence on social attitudes: Another challenge to psychology from behavior genetics. In L. F. DeLilla (ed.) Behavior Genetic Principles: Development, Personality, and Psychopathology, pp. 89-104. Washington, DC: American Psychological Association.
Brim, O. G., C. D. RyFF, and R. C. Kessler. 2004. The MIDUS National Survey: An overview. In O. G. Brim, C. D. Ryff, and R. C. Kessler (eds.), How Healthy Are We? A National Study of Well-Being at Midlife, pp. 64-89. Chicago: University of Chicago Press.

Brim, O. G., P. B. Baltes, L. L. Blumpass, P. D. Cleary, D. L. Featherman, W. R. Hazzard, R. C. Kessler, M. E. Lachman, H. R. Markus, M. G. Marmot, A. S. Rossi, C. D. RYFF, and R. A. SHweder. 2000. National survey of midlife development in the United States (MIDUS), 1995-1996 [Computer file]. ICSPR version. Ann Arbor, MI: DataStat, Inc./Boston, MA: Harvard Medical School Dept. of Health Care Policy [producers], 1996. Ann Arbor, MI: Inter-university Consortium for Political Research [distributor], 2000.

Charlesworth, B. 1980 . Evolution and agestructured populations. Cambridge: Cambridge University Press.

ELLIS, L. 1987. Criminal behavior and $\mathbf{r} / \mathrm{K}$ selection: An extension of gene-based evolutionary theory. Deviant Behavior 8(2): 149-176.

FALCONER, D. S. 1989. Introduction to quantitative genetics, 3rd ed. Essex: Longman Scientific and Technical.

Figuerdo, A. J. 2000. Commentary on chapters 10-14: Genetic influences on sexuality, marriage, and reproduction. In J. L. Rodgers, D. C. Rowe, and W. B. Miller (eds.), Genetic Influences on Human Fertility and Sexuality: Theoretical and Empirical Contributions for the Biological and Behavioral Sciences, pp. 317-323. Norwell, MA: Kluwer Academic Publishers.

Figuerdo, A. J., J. SEFCEK, and D. N. JONES. 2006. The ideal romantic partner. Personality and Individual Difference, in press.

Figuerdo, A. J., G. VÁsquez, B. H. Brumbach, and S. SCHNEIDER. In press. The K-factor, covitality, and personality: A psychometric test of life history theory. Human Nature.

Figuerdo, A. J., J. A. Sefcek, G. Vásquez, B. H. BRUMBACH, J. E. KING, and W. J. JACOBS. 2005. Evolutionary theories of personality. $\ln$ D. M Buss (ed.), Handbook of Evolutionary Psychology, pp. 851-877. Hoboken, NJ: Wiley.

Figuerdo, A. J., G. Vásquez, B. H. Brumbach, J. SEFCEK, B. R. KIRSNER, and W. J. JaCOBS. 2005. The K-factor: Individual differences in life history strategy. Personality and Individual Differences 39(8):1349-1360. 
Figuerdo, A. J., V. Corral-Verdugo, M. FriasARMENTA, K. J. Bachar, J. White, P. L. MCNeill, B. R. Kirsner, and I. P. Castell-Ruiz. 2001. Blood, solidarity, status, and honor: The sexual balance of power and spousal abuse in Sonora, Mexico. Evolution and Human Behavior 2:295-328.

Goldsmith, H., M. A. Gernsbacher, J. Crabbe, G. Dawson, I. I. GotTesman, J. HewitT, M. McGue, N. Pedersen, R. Plomin, R. Rose, and J. SWANSON. 2003. Research psychologists' roles in the genetic revolution. American Psychologist 58(4):318-319.

GOTTFREDSON, L. S. Social consequences of group differences in cognitive ability. Consequencias sociais das diferencas de grupo em habilidade cognitive. In C. E. Flores-Mendoza and R. Colom (eds.), Introduca a psicologia das direrencas individuals, in press. Porto Allegre, Brazil: ArtMed Publishers

Grant, S. G. N. 2003. An integrative neuroscience program linking mouse genes to cognition and disease. In R. Plomin, J. C. Defries, I. W. Craig, and P. McGuffin (eds.), Behavioral Genetics in the Postgenomic Era, pp. 124-138. Washington, D.C.: American Psychological Association.

HuR, Y. M., and T. J. BouchaRD. 1995. Genetic influences on perceptions of childhood family environment: A reared apart twin study. Child Development 66:330-345.

HuR, Y., and T. J. BouCHARD. 1997. The genetic correlation between impulsivity and sensation traits. Behavior Genetics 27(5):455-463.

JOHNSON, W., and R. F. KRUEGER. 2004. Genetic and environmental structure of adjectives describing the domains of the Big Five Model of personality: A nationwide US twin study. Journal of Research in Personality 38:448-472.

Johnson, W., M. MCGUE, R. F. KRUEGER, and T. J. BOUCHARD. 2004. Marriage and personality: A genetic analysis. Journal of Personality and Social Psychology 86(2):285-294.

KaWACHI, I., B. P. KENNEDY, and R. G. WILKINSON. 1999. The society and population health reader, Volume 1: Income inequality and health. New York: New Press.

KerCKhof, A. C. 2000. Generating social stratification: Toward a new research agenda. Boulder, CO: Greenwood Press.

KERI, S. 2003. Genetics, psychology, and determinism. American Psychologist 58(4):319.

Kirk, K. M., S. P. BlomberG, D. L. DufFy, A. C. Heath, I. F. P. OWens, and N. G. Martin. 2001. Natural selection and quantitative genetics of life-history traits in western women: A twin study. Evolution 55(2):423-435.

KrUEgER, R. F., K. E. MARKon, and T. J. Bouchard. 2003. The extended genotype: The heritability of personality accounts for the heritability of recalled family environments in twins reared apart. Journal of Personality 71(5):809-833.

Luciano, M., M. J. Wright, G. A. SMith, G. M. GefFen, L. B. GefFen, and N. G. Martin. 2003. Genetic covariance between processing speed and IQ. In R. Plomin, J. C. Defries, I. W. Craig, and P. McGuffin (eds.), Behavioral Genetics in the Postgenomic Era, pp. 163-182. Washington, D.C.: American Psychological Association.

MACARTHUR, R. H., and E. O. WILSON. 1967. The theory of island biogeography. Princeton, NJ: Princeton University Press.

McCrae, R. R., K. L. JANG, W. J. Livesley, R. RiEMANN, and A. ANGLEITNER. 2001. Sources of structure: Genetic, environmental, and artifactual influences on the covariance of personality traits. Journal of Personality 69:51 1-535.

McGue, M. K. 1992. When assessing twin concordance, use the probandwise and not the pairwise rate. Schizophrenia Bulletin 18:171-176.

Miller, G. F. 2000. The mating mind: How sexual choice shapes the evolution of human nature. New York: Doubleday.

PIANKA, E. R. 1970. On r- or K-selection. American Naturalist 104:592-596.

Plomin, R., and J. CrabBe. 2000. DNA. Psychological Bulletin 12(6):806-828.

Plomin, R., and M. RutTer. 1998. Child development, molecular genetics, and what to do with genes once they are found. Child Development 69(4): 1223-1 242.

Plomin, R., J. C. Defries, I. W. Craig, and P. McGuffin. 2003. Behavioral genetics. In R. Plomin, J. C. Defries, I. W. Craig, and P. McGuffin (eds.), Behavioral Genetics in the Postgenomic Era, pp. 3-15. Washington, D.C.: American Psychological Association.

QUINLAN, R. 2003. Father-absence, parental care, and female reproductive development. Evolution \& Human Behavior 24(6):376-390.

REZNICK, B., M. J. BRYANT, and F. BAHSEY. 2002. rand $\mathrm{K}$-selection revisited: The role of population regulation in life-history evolution. Ecology 83(6): $1509-1520$.

RisCH, N. J. 2000. Searching for genetic determinants in the new millenium. Nature 405:847-856.

Rodgers, J. L., K. Hughes, H.-P. KOHLER, K. Christensen, D. Doughty, D. C. Rowe, and W. B. MiLler. 2001. Genetic influence helps explain variation in human fertility outcomes: Evidence from recent behavioral and molecular genetic studies. Current Directions in Psychological Science 10: 184-188.

Rossi, A. S. 2001. Contemporary dialogue on civil society and social responsibility. In A. S. Rossi (ed.), Caring and Doing for Others: Social Responsibility in the Domains of Family, Work, and Community, pp. 3-75. Chicago, IL: The University of Chicago Press.

Rowe, D. C. 1994. The limits of family influence: Genes, experience and behaviour. New York: Guilford.

2000. Environmental and genetic influences on pubertal development: Evolutionary life history traits? In J. L. Rodgers, D. C. Rowe, and W. B. Miller (eds.), Genetic Influences on Human Fertility and Sexuality, pp. 147-168. Boston: Kluwer. 
2003. Assessing genotype-environment interactions and correlations in the postgenomic era. In R. Plomin, J. C. Defries, 1. W. Craig, and P. McGuffin (eds.), Behavioral Genetics in the Postgenomic Era, pp. 71-86. Washington, D.C.: American Psychological Association.

Rowe, D. C., and D. J. Flannery. 1994. An examination of environmental and trait influences on adolescent delinquency. Journal of Research in Crime and Delinquency 31(4):364-379.

Rowe, D. C., and J. L. Rodgers. 1989. Behavior genetics, adolescent deviance, and "d": Contributions and issues. In G. Adams, R. Montemayor, and T. Gullotta (eds.), Advances in Adolescent Development, pp. 38-70. Newbury Park, CA: Sage.

Rowe, D. C., A. T. Vazsonyi, and A. J. Figueredo. 1997. Mating effort in adolescence: Conditional or alternative strategy? Personality and Individual Differences 23(1): 105-1 15.

Rushton, J. P. 1985. Differential K theory: The sociobiology of individual and group differences. Personality and Individual Differences 6(4):441-452.

. 1987. An evolutionary theory of health, longevity, and personality: Sociobiology and $r / K$ reproductive strategies. Psychological Reports 60:539-549.

2000. Race, evolution, and behavior: A lifehistory perspective (3rd Edition). Port Huron, MI: Charles Darwin Research Institute.

2004. Placing intelligence into an evolutionary framework or how $\mathrm{g}$ fits into the $\mathrm{r}-\mathrm{K}$ matrix of life history traits including longevity. Intelligence 32:32l-328.

SAS INSTITUTE, INC. 1999. SAS/STAT User's Guide, Version 8, Volumes 1, 2, and 3. Cary, NC: SAS Institute.
Stearns, S. C. 1992. The evolution of life histories. Oxford: Oxford University Press.

Tal, I., D. Hill, A. J. Figueredo, M. FríasARMENTA, and V. Corral-Verdugo. In press. Reproductive life history strategy and water conservation. Medio Ambiente y Comportamiento Humano.

Tellegen, A. 1982. Brief manual for the Differential Personality Questionnaire, unpublished manuscript. Minneapolis: University of Minnesota.

ThornhiLl, R., and C. T. PALMER. 2004. Evolutionary life history perspective on rape. In C. Crawford and C. Salmon (eds.), Evolutionary Psychology, Public Policy and Personal Decisions, pp. 249-274. Mahway, NJ: Lawrence Erlbaum.

Waller, N. G., B. A. Kojetin, T. J. Bouchard, D. T. LyKken, and A. Tellegen. 1990. Genetic and environmental influences on religious interests, attitudes, and values: A study of twins reared apart and together. Psychological Science 1(2): 138-142.

Weiss, A. J., J. E. KING, and R. M. ENNS. 2002. Subjective well-being is heritable and genetically correlated with dominance in chimpanzees. Journal of Personality and Social Psychology 83:1141-1149.

Wilbur, H. M., D. W. Tinkle, and J. P. Collins. 1974. Environmental certainty, trophic level, and resource availability in life history evolution. The American Naturalist 108:805-817.

WILKINSON, R. 1996. Unhealthy societies: The afflictions of inequality. London: Routledge.

WILSON, E. O. 1975. Sociobiology: The new synthesis. Cambridge, MA: Harvard University.

ZuCKERMAN, M. 1979. Sensation seeking: Beyond the optimal level of arousal. Hillsdale, $\mathrm{NJ}$ : Lawrence Erlbaum Associates. 
Copyright of Social Biology is the property of Social Biology and its content may not be copied or emailed to multiple sites or posted to a listserv without the copyright holder's express written permission. However, users may print, download, or email articles for individual use. 